\title{
Bojack Horseman's Existentialism and the Nuances of Representation of Mental Health
}

\author{
Asmita Singh \\ A Postgraduate Student \\ English Literature with Communication Studies \\ Christ (Deemed to be) University, India
}

\begin{abstract}
Contemporary pop culture and media, especially the ones targeted at young individuals, are beginning to get the rightful recognition, deservedly so. Psychologists, researchers are shifting the focus on the validity of media (Broadcast media in particular like Television, Podcasts, in shaping one's perception of mental health and illness. OTT platforms such as Amazon Prime, Netflix, and Hotstar, among many others, and the content produced on those have exponentially influenced the lives of so many. As they exercise more freedom than traditional media, they explore uncharted territories in terms of their content, as is obvious because of the lack of censorship. OTT platforms have observed an upward curve in their popularity and usage, especially on account of the depiction of varied themes and subjects like mental illness, therapy, and millennial psychology. Consumption patterns have shifted tremendously, especially in unprecedented confinement. Millennials prefer to consume a lot of online content streamed on these platforms. Qualitative descriptive data in the form of the visual text comes from the Netflix original, Bojack Horseman, while simultaneously applying autoethnographic research technique to understand the depiction of mental health in the show; analyzing the show's existentialist tools to relieve millennial angst brought on by the unbearableness of human existence.
\end{abstract}

Keywords- Anxiety, Millennial Psychology, Existentialism, Meaning, Mental Health.

(OPerception Publishing House, 2021. This Open Access article is published under a Creative Commons Attribution NonCommercial 4.0 International License https://creativecommons.org/licenses/by-nc/4.0/, which permits non-commercial re-use, distribution, and reproduction in any medium, provided the original work is properly cited. For citation use the DOI. For commercial re-use, please contact editor @ email:- thecreativelauncher@gmail.com 


\section{Introduction}

The streaming top dog Netflix has an array of options suited for all age groups and produces a lot of powerful, inspirational, and soul-touching content for their viewers. With the recent psychological awakening and fundamental acceptance of various subjects revolving around issues of mental health, there has been staggering growth in the portrayal of the aforementioned themes in shows like Breaking Bad (2008-2013; Created and Produced by Vince Gillian, AMC network), Fleabag (2016-2019; Created and Written by Phoebe Waller-Bridge, BBC Three), 13 Reasons Why (2017-2020; Developed by Brian Yorkey, Netflix), Shameless (2011-2021; developed by John Wells, Showtime), This Is Us (2016-2021; created by Don Fogelman, NBC), and of course, Bojack Horseman (2014-2020; created by Raphael BobWaksberg, Netflix) which has gained a cult following because of its inordinately accurate grasp of mental health. Keeping in mind such depictions and their portrayals, this paper aims to analyze the depiction of mental illness in the Netflix original show, Bojack Horseman.

Bojack Horseman is very distinctive from other representations of mental health in media, on account of its in-depth and soul-crushing take on not just depression but also anxiety, Bi-Polar Disorder, Borderline Personality Disorder, PTSD, ADD, and the quintessential High Functioning Depression. The show focuses on all facets of mental health issues and continually highlights the ugly side of mental illnesses which is why it becomes imperative to the study of millennial psychology. The purpose is to understand the depiction of the human condition, sexuality, trauma, and self-destructive tendencies in young adults in a very jarringly realistic manner paralleled with humor as a defense mechanism; IndieWire called it the greatest animated television series of all time and the GQ Magazine regards the show as one that addressed hotbutton socio political issues, thus becoming the primary reason the show resonates with most of its audience. Another purpose is to briefly understand millennial existentialism through Bojack Horseman to understand the need for a stable "meaning", exploring millennial psychology. These themes were further explored by philosophers and other researchers after the conceptualization of Existential theories by Jean-Paul Sarte and Albert Camus, which mainly focused on the subjectivity of human existence in terms of religion, freedom, guilt, or regret as opposed to keeping objective knowledge and science in centrality. They explored the freedom of human imagination; the Sartrean variety follows the mantra existence precedes essence, whereas Camus's Absurdism focuses on the irrational nature of life and on the boundless, untamed fury at 
the absurdity of existence; the meaningless struggle to find a purpose in life. Their theories lay the groundwork for millennial psychology and the need for a 'meaning' in life, that often paves the way to some serious mental health issues because of the severity of the existential angst experienced, driven by a culture of achievement in a world that threatens individual safety. Bojack Horseman is the primary source that uses these theories as a means to resolve the existential angst that a lot of millennials experience by perpetuating the idea that there is no evident meaning or sense of purpose in life. Secondary sources include assorted academic journals and databases from libraries in the form of research articles produced in the same field of research obtained from sources such as JSTOR, Google scholar, sage publications, etc as they have proven to be abundantly insightful, and assist in the critical analysis of the aforementioned theories. Textual analysis and Discourse analysis were conducted on the same descriptive data.

\section{Trauma and Freedom of Choice.}

Netflix brings one to the world of Bojack Horseman where the audiences follow the life of an unhappy, washed-up, and aging star who is half-human, half-horse. It is set up in an alternate universe where humans, animals, and their hybrids live alongside each other. At first, Bojack comes across as simply a pessimistic person stuck in his past, making miserable decisions, one who awaits his quintessential happy ending. Whilst the show progresses, the audience begins to understand that Bojack is not an antihero but a cautionary tale looking for meaning in nothingness (Parashar, 2020).

Bojack has gained momentum because it captures the essence of cinema vérité while addressing depression, anxiety, bereavement, trauma, and abortion. It has a very satirical and nuanced approach to acknowledging and critiquing social issues like alcoholism, drug addiction, politics, capitalism, and current affairs. Bojack enables the audiences to discover a very confessional memoir of the battles of mental health and this psychiatric familiarization sets the show apart from others' portrayal of the introductory issues (Lahut, 2017).

The titular character is a drunkard with rather wounded masculinity who can oftentimes be self-aggrandizing, narcissistic, and emotionally abusive. However, the show does not aim at narrowing down one specific cause for the trauma suffered by any of its central characters that shall then justify their own suffering or toxic traits and treatment of others because such depiction is negligent and lackadaisical. This hasty generalization is inherently 
counterproductive to raising awareness of mental health issues and does not help destigmatize mental illness.

Sartre in Existentialism Is a Humanism (1948), elaborated on the nature of human existence and freedom which was later developed into an account of existential philosophy. He argued that human beings cannot be categorized into generalized vague labels or descriptors as they have no fixed essence. In this regard, Bojack Horseman tries to reiterate the idea that any suffering or trauma is not the identity of anyone.

Human existence has no specific psychological traits that concludingly define individualistic nature, that is to say, that the only defining characteristic of an individual is the way they choose to live their life freely. This brings forward the argument that individuals can choose to think of their freedom in a manner that is not burdening but liberating to their existence as opposed to fixating on their existential angst and suffering and refusing to accept accountability for one's action or happiness (Sartre 1958, p. 61).

The Creator of the show further suggests that there is not just one circumstance or event that necessarily points out or defines one's trauma and the reason for their self-destructive behavior. (Shearman, 2017). Bojack Horseman very explicitly tries to delve into portraying human desires, trauma, and the ever-evolving "meaning" of existence that becomes a driving force amongst most millennials. Simultaneously, this incessant need for a purpose forces one to look at the infinite freedom at human disposal as burdensome and can pave the way for a deeply sickening feeling of existential dread and angst.

\section{Bad Faith}

There persists an illegitimate suspicion in our minds about the choices we've made. A beleaguered Bojack thus flees away from freedom and responsibility, and pretends he has no choice at his disposal. Taking responsibility for one's actions comes with a lot of challenges, it involves opening a difficult dialogue with oneself as opposed to retreating into corners that are governed by social norms and order.

Sartre postulated the idea that the reasoning or rationality of "no choice" was pointless and suggested that this was a lie an individual told themselves to account for their toxic traits that stems from a mental illness or abuse. (Sartre, 1956)

Poorva Parashar suggested that "bad faith" removes the burden of realizing that choices have to be made and responsibilities towards those choices are to be owned too. However, this 
hypothesis merely remains a vague dichotomization of a few individuals' approach to accountability in life for their actions or to their approach to self-destructive behavior. It stands its ground in Bojack's case as he distinguishes between his narcissistic self and his "good self" who largely remains absolved of any responsibility. Bojack prefers a state of complete denial where "a person refuses to acknowledge anxiety- arousing aspects of the environment" (Passer \& Smith, 2013, p. 463).

The show is against the idea of using past traumas as an excuse for toxic behavior towards others, and to account for current misery. This pivotal moment in the show occurs when Bojack's friend, Todd Chavez demands accountability after reaching a breaking point in their friendship. In his words- "Oh great, of course! Here it comes! You can't keep doing this! You can't keep doing shitty things and then feel bad about yourself like that makes it okay! You need to be better! You are all the things that are wrong with you. It's not the alcohol or the drugs or any of the shitty things that happened to you in your career or when you were a kid, it's you! Okay? It's you. Fuck, man, what else is there to say?" (Season 3, Episode 10).

Several nerve-wracking complexities that arise on account of other forms of bad faith can be observed in romantic relationships as well as in relationships developed during the childhood of other principal characters like Diane Nguyen and Princess Carolyn who are friends with Bojack. The show highlights instances when one relinquishes one's personal freedom, thus allowing oneself to become an object that is freely defined with respect to the relationship they have with someone. This enables viewers to acquaint themselves with the problematic nature of bad faith in exhaustive detail (Froio, 2020).

\section{Millennial Psychology and "Meaning" of Life.}

Existentialist themes also have their roots in Samuel Beckett's Waiting for Godot which relates unprecedented leisure time to despair and existential angst, especially amongst millennials which the show explores through Todd who is seemingly content with the life he has unless he is free; spare time results in him being grief-stricken simply because of his senseless existence just like the two men in Beckett's magnum opus who eat, sleep, sing, argue, contemplate suicide-anything to hold the terrible silence at bay. It is the natural poverty of our feeble and mortal condition which is so miserable and nothing can comfort anyone when they think of it closely (Pascal \& Havet, 1852). 
The perspective of the show remains to highlight the fact that there are no satisfactory endings or resolutions to life that shall add meaning or a sense of purpose to one's worth or life. The storyline consistently denies its viewers of happy endings to reiterate the idea that there is no ideal happy ending that is coming in the face of this absurdity. All the happiness one derives from life is through experiences, both good and bad. The aim of it as suggested by Mr. Peanutbutter is to keep oneself distracted and occupied with unimportant nonsense until death.

This portrayal of human perception and millennial psychology in its different facets allows for self-reflection in the audience on various grounds because it offers solace and comfort in dealing with, and finding a healthy mechanism for coping with mental health. It brings to the surface the relationship between unresolved past trauma and inherited personal trauma, and the tragic impact of the two operating together on an individual (Barker, 2020).

Bojack Horseman as a show provides exponential data to the study of millennial psychology to researchers in the treatment of mental illness because it helps understand the public perception of such issues after constant interrogation into the inner psyche of its audience; thus enabling empathetic understanding in individuals. Social learning theory suggests that exposure of individuals to people with mental illness on television and the media portrayals define and describe the differential treatment of those with mental illnesses (Stout, et al., 2004).

\section{Conclusion}

Through its exploration of existentialist theory, Bojack Horseman remains consistent with its existentialist and absurdist foundations which necessitates a recognition of the eventual absurdity of the pursuit of happiness, closely tied with dark, self-deprecating humor. (Parashar, 2020). Bojack Horseman breaks away from the conventions of sitcoms and creates a new category for itself, its superiority over other shows is established by the fact that it priorities different values and facts that are grounded in philosophy to address the issues arising out of the banalities of life, instead of projecting the hopelessness to be used as a nihilistic tool. The selfreflective critique, which can be seen throughout Bojack Horseman's narrative arc is its strongest tool to tackle existentialist angst arising out of the mortality of human condition, which, in hindsight substantiates the show's supremacy. On the basis of this hard-hitting, realistic stance of the show on sociopolitical issues, its validity further strengthens the understanding of millennial psychology. 


\section{References}

Bob-Waksberg, R. (Creator). Bojack Horseman [Television series]. Netflix, 2014.

Camus, A. An absurd reasoning. "The Myth of Sisyphus and Other Essays". New York: Vinatge Books, 1955.

Sartre, J. P. "Being and Nothingness", (H.E. Barnes,Trans.). New York: Philosophical Library, 1956.

Sartre, Jean-Paul, and Philip Mairet. Existentialism and Humanism. Haskell House, 1948. Print.

Bob-Waksberg, R. (Writer), \& Cendreda, M. (Director). "Later" [Television seriesepisode] In Bob-Waksberg, R. (Executive Producer), Bojack Horseman. Netflix, 2014.

Santamaria, Vera (Writer), \& Parton, Adam (Director), “It's You” [Television seriesepisode] In Bob-Waksberg, R. (Executive Producer), Bojack Horseman. Netflix, 2016.

Lahut, J. The Forbidden Genre: "The Evolution of the Psychiatric Memoir and the Narrativity of Madness Pre-and Post DSM”. Wesleyan University: Middletown, Connecticut, 2017.

Parashar, Poorva. "Bojack Horseman and Mental Health : An Academic Exploration of Existentialist Themes". Pascal, B., \& Havet, E. (1852). Pensées. Dezobry et E.Magdeleine, May 2020.

Shearman, S. (2017, September 28). The Existentialism of BoJack Horseman. Retrieved January 29, 2021, from https://fee.org/articles/the-existentialism-of-bojack- horseman/

Froio, Nicole. From Leaving Hollywoo: Essays After Bojack Horseman, Nov 2020. Post45.org. Post45, retrieved on 20 March, 2021.

Barker, Liam, "Mental Illness and Personal Trauma: Why We Joke About Wanting to Kill Ourselves" (2020). 2020 JHU Richard Macksey National Undergraduate Humanities Research Symposium. 155.

https://www.mackseysymposium.org/virtual2020/all/presentations/155

Mambrol, Nashrullah. "Key Theories of Jean Paul Sartre”, June 2017. Literary Theory and Criticism. Literariness.org. Web. Retrieved Feb 18, 2020.

https://literariness.org/2017/06/08/key-theories-of-jean-paul-sartre/

Passer, M. W., \& Smith, R. E. "Psychology: The Science of Mind and Behaviour (5 ${ }^{\text {th }}$ Ed.)". McGraw Hill Education India: New Delhi, 2013. 